University of Nebraska - Lincoln

DigitalCommons@University of Nebraska - Lincoln

8-2007

\title{
The Evolution of Color Polymorphism: Crypticity, Searching Images, and Apostatic Selection
}

Alan B. Bond

University of Nebraska - Lincoln, abond1@unl.edu

Follow this and additional works at: https://digitalcommons.unl.edu/bioscifacpub

Part of the Life Sciences Commons

Bond, Alan B., "The Evolution of Color Polymorphism: Crypticity, Searching Images, and Apostatic Selection" (2007). Faculty Publications in the Biological Sciences. 52.

https://digitalcommons.unl.edu/bioscifacpub/52

This Article is brought to you for free and open access by the Papers in the Biological Sciences at DigitalCommons@University of Nebraska - Lincoln. It has been accepted for inclusion in Faculty Publications in the Biological Sciences by an authorized administrator of DigitalCommons@University of Nebraska - Lincoln. 
Published in Annual Review of Ecology, Evolution, and Systematics 38 (2007), pp. 489-514; doi: 10.1146/annurev.ecolsys.38.091206.095728

Copyright (C) 2007 Annual Reviews. Used by permission.

Published online August 15, 2007; volume publication date December 2007

\title{
The Evolution of Color Polymorphism: Crypticity, Searching Images, and Apostatic Selection
}

\author{
Alan B. Bond \\ School of Biological Sciences, \\ University of Nebraska-Lincoln, \\ Lincoln, NE 68588 \\ email: abond1@unl.edu
}

\begin{abstract}
The development and maintenance of color polymorphism in cryptic prey species is a source of enduring fascination, in part because it appears to result from selective processes operating across multiple levels of analysis, ranging from cognitive psychology to population ecology. Since the 1960s, prey species with diverse phenotypes have been viewed as the evolved reflection of the perceptual and cognitive characteristics of their predators. Because it is harder to search simultaneously for two or more cryptic prey types than to search for only one, visual predators should tend to focus on the most abundant forms and effectively overlook the others. The result should be frequency-dependent, apostatic selection, which will tend to stabilize the prey polymorphism. Validating this elegant hypothesis has been difficult, and many details have been established only relatively recently. This review clarifies the argument for a perceptual selective mechanism and examines the relevant experimental evidence.
\end{abstract}




\section{Introduction}

Edward Poulton's classic work, The Colours of Animals (1890), provided the first evolutionary account of cryptic coloration, focusing particularly on woodland moths that adopt the color patterns of leaves, twigs, and bark. Poulton noted that these insects were often polymorphic, occurring in multiple distinctive pattern variants, and he suggested that this served to reduce the efficiency of predatory search. He wrote that polymorphism provides "a wider range of objects for which [predators] may mistake the larvae, and the search must occupy more time, for equivalent results, than in the case of other species which are not dimorphic" (Poulton 1890, p. 47). Polymorphism was thus viewed from the outset as an adaptive response to the behavior of visual predators, but confirming the selective mechanism has proved a subtle and complex task. Although other aspects of the evolution of polymorphism have recently been reviewed (Hedrick 2006, Sinervo \& Calsbeek 2006), the selective role of predator cognition has not been fully developed and critically discussed in many years. The argument has three main premises: (a) Visual search is subject to processing limitations, in that it is more difficult to search for two or more dissimilar, cryptic prey types simultaneously than to search for only one. $(b)$ Predators consequently tend to focus on the most rewarding prey type and effectively overlook the others. (c) The result is frequency-dependent, apostatic selection, a higher relative mortality among more abundant prey types that serves to stabilize prey polymorphism. We briefly discuss cryptic coloration and color polymorphism, and then consider each premise of the argument in turn.

\section{Components of Crypticity}

Cryptic or concealing coloration allows prey animals to blend into the background, reducing their vulnerability to visually searching predators (Cott 1957, Edmunds 1974). Crypticity is an intuitively accessible concept, but it resists easy quantification. It is usually used to describe whether a prey animal looks like its surroundings or whether human observers can easily detect it. This usage might be better termed detectability than crypticity, as it varies with the observation conditions, the characteristics of the predator's visual system, and short-term changes in the predator's focus of attention and searching speed. To reduce ambiguity, Endler (1991) defined a cryptic color pattern as one that "resembles a random sample of the visual background," conditioned by the biophysics of predator vision and the characteristics of the ambient illumination. This was a significant conceptual advance, but the notion of random sampling is open to competing methodological interpretations. Merilaita \& Lind (2005) extracted prey-shaped pieces from arbitrary locations in a textured background. They showed that the resulting stimuli were highly variable in appearance, and many were very easy to detect.

Using a cookie-cutter on the background may, however, be less appropriate as a model of crypticity than it is of pattern mimicry. In this phenomenon, which has also been termed special resemblance (Cott 1957) or masquerade (Endler 1981), the animal evolves a detailed likeness to some specific, local feature of its envi- 
ronment (Edmunds 1990, Robinson 1969, Vane-Wright 1980). Pattern mimicry has produced some of the most spectacular examples of protective coloration, such as stick caterpillars (de Ruiter 1952), leaf-mimicking katydids (Castner \& Nickle 1995), and leafy seadragons (Connolly et al. 2002). However, most cryptically colored species display a more global, statistical resemblance to the background, in which the wavelength, intensity, and size of prey color patches converge on the mean of a multivariate distribution of background features. Endler (1978, 1984) proposed to extract such statistical distributions for both the background and the prey and to measure crypticity in terms of the correspondence between the distributions. In studies of the ability of blue jays to detect artificial moths on randomly textured backgrounds, a similar statistical measure accounted for $30 \%-40 \%$ of the variance in detection accuracy (Bond \& Kamil 1999, Kamil \& Bond 2001).

In addition to detectability and crypticity, a third component in the effectiveness of concealing coloration is the configuration of the background. An intricate and complex background containing many contrasting elements over a range of spatial frequencies can require a prolonged and careful search, even if the prey are not otherwise particularly cryptic (Bond \& Kamil 2006, Merilaita 2003, Robinson 1990). This is the basis for the visual puzzles in many children's books (e.g., Handford 1987), in which the task is to locate a particular item in a highly detailed and cluttered image. There may be only a limited resemblance between the item and the distracting elements of the background, but because there is so much information to be processed, the search can be very laborious. The impact of complexity is illustrated in Figure 1, which displays a set of six artificial moths on four differently textured backgrounds. The intensity histogram of the background in Figure $1 \mathrm{~b}$ corresponds closely to that of the moths, but the average spatial frequency is somewhat higher. The distinctive patterns of local spatial correlations in the moths draw the viewer's attention, forming a contrast to the uncorrelated features of the background. In Figure 1c, the background pixels were drawn from independent light and dark intensity distributions that minimally overlapped those of the moths, but the average spatial frequency was reduced, increasing the visual complexity of the texture. These moths are less cryptic, in terms of statistical resemblance, than those in Figure $1 b$, but both humans and blue jays find them far more difficult to detect.

\section{Categories of Color Polymorphism}

Color polymorphism is widely distributed among cryptic prey species. It has been studied extensively in pulmonate snails (Cain \& Sheppard 1954, Clarke et al. 1978, Cook 1998), but it is common among other mollusks as well (e.g., Atkinson \& Warwick 1983, Whiteley et al. 1997). There are cryptic polymorphic spiders (Bonte \& Maelfait 2004, Oxford \& Gillespie 1998), crustaceans (Devin et al. 2004, Hargeby et al. 2004, Merilaita et al. 2001), and even vertebrates (Olendorf et al. 2006, Wente \& Phillips 2003). Examples occur throughout the Acridid and Tetrigid grasshoppers (Figure 2) (Dearn 1990, Nabours et al. 1933), where many species are so variable that color is wholly inadequate as a basis for classification (Rowell 1971). Many mantids (Edmunds 1976) and katydids (Owen 1980) are polymorphic, as are water boatmen (Popham 1941), walking sticks (Sando- 

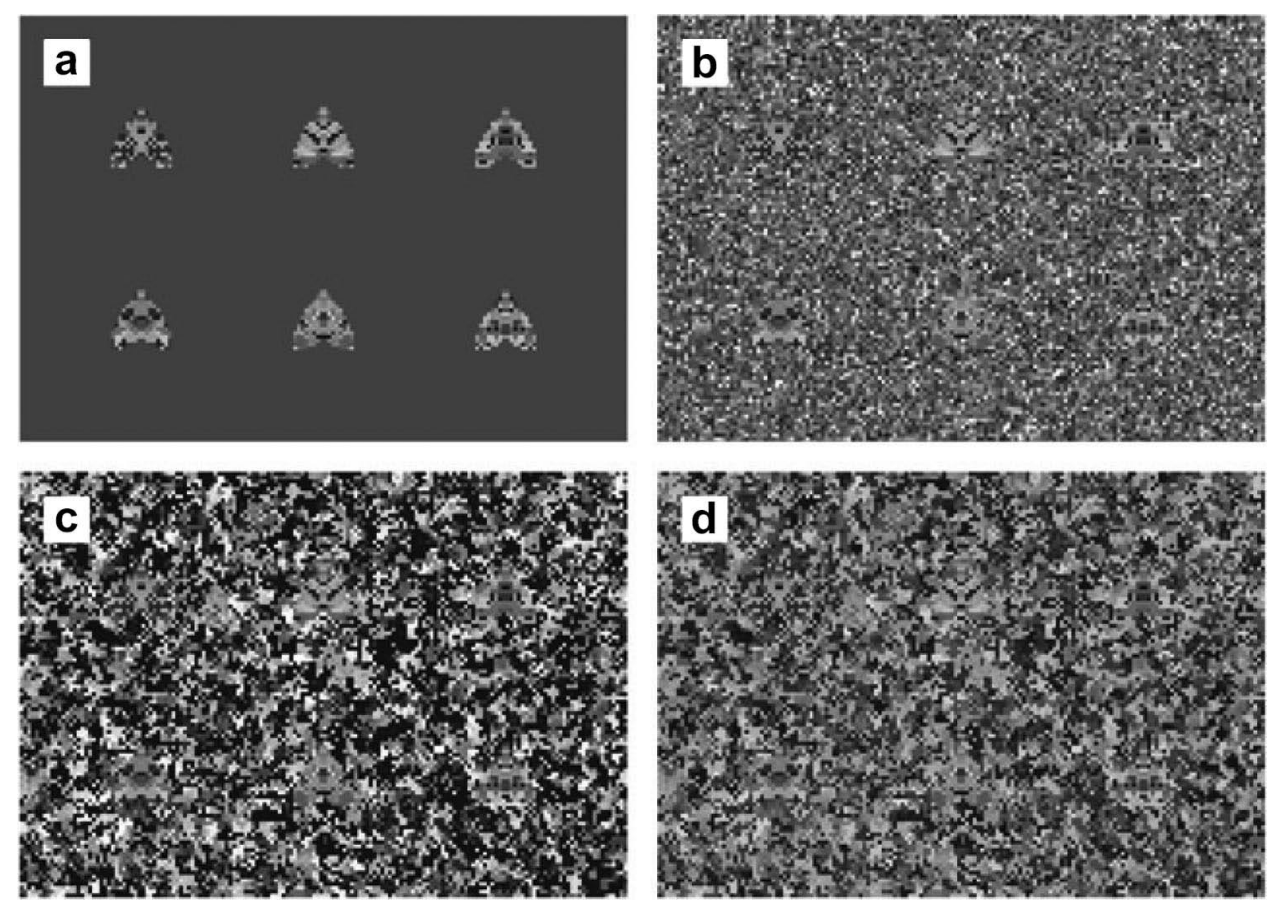

Figure I. Artificial moths on backgrounds of varying crypticity and complexity. (a) Uniform dark gray background. (b) Intensity histogram of background matches that of the moths; mean spatial frequency is somewhat higher. (c) Background constructed from a bimodal intensity histogram that minimally overlaps the moth distribution; mean spatial frequency is comparable to that of moths. (d) Background matches moths in both pixel intensity and spatial frequency.

val 1994), and spittlebugs (Halkka \& Halkka 1990). Perhaps the best-researched examples of color polymorphism are found among moths, in which both the larvae and the adults are usually cryptically colored and frequently polymorphic (Greene 1996, Janzen 1984, Kettlewell 1973, Poulton 1890, Sargent 1976). In some moth taxa, polymorphism is pervasive: Roughly $40 \%$ of the species in Barnes \& McDunnough's (1918) survey of the underwing moths of North America occur in multiple distinctive forms.

Polymorphic species can be separated into two broad categories that appear to reflect distinguishable evolutionary strategies. One grouping consists of species that occur in many disparate forms, all of which bear a general resemblance to the same background. The number of morphs can range from perhaps three or four to dozens, as in grouse locusts (Acrydium arenosum) (Figure 2) (Nabours et al. 1933), land snails (Cepaea nemoralis) (Cain \& Sheppard 1954), or underwing moths (Catocala micronympha) (Barnes \& McDunnough 1918). Such generalist polymorphisms are mainly associated with relatively homogeneous but visually complex environments, such as temperate grasslands, exposed rock and soil, leaf litter, or beach gravel (Clarke et al. 1978, Dearn 1990, Rowell 1971, Whiteley et al. 1997). These habitats tend to be fine grained (Levins 1968), in that there are no large patches of distinctive substrate, but the visual complexity enables a range of diverse forms to be equally difficult to detect. In the most 


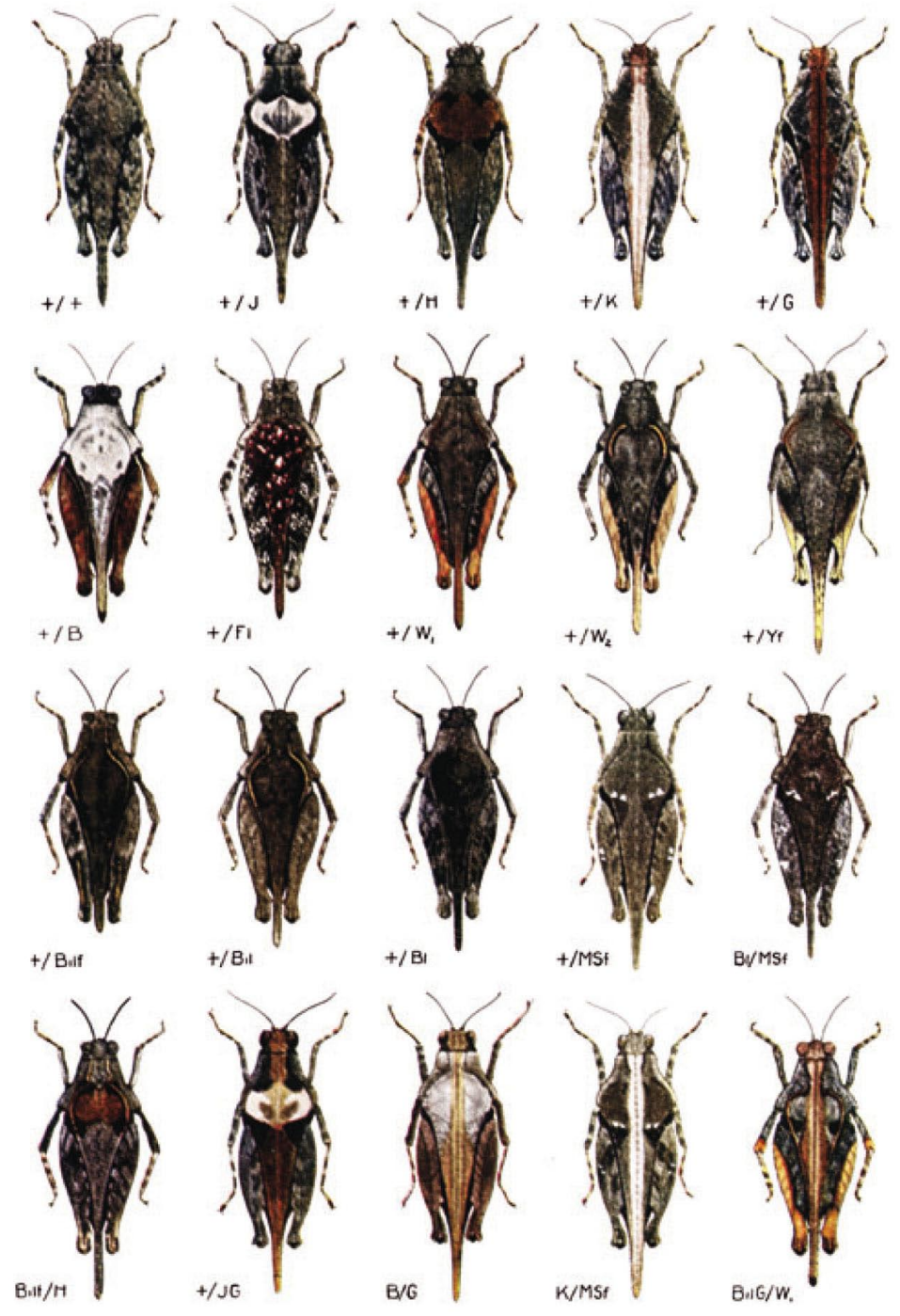

Figure 2. A selection of morphs of Acrydium arenosum, a highly polymorphic grouse locust from central Kansas. Reprinted from Nabours et al. (1933) by permission of the Genetics Society of America. Copyright is retained by the Genetics Society of America.

extreme cases, generalist species can be massively polymorphic, occurring in an essentially unlimited number of forms. The original example is Donacilla cornea, a European beach clam (Whiteley et al. 1997), but there are other organisms that may be similarly unrestricted in their morph diversity [e.g., bogong moths: Agrotis infusa (Common 1954) or brittlestars: Ophiopholis aculeata (Moment 1962)].

A second group of polymorphic species are associated with heterogeneous environments that are divided into large, disparate substrate patches (Bond \& Kamil 2006, Merilaita et al. 2001). In such coarse-grained habitats (Levins 1968), an individual can occupy only one substrate type at a time and, because of the dis- 
parity in patch appearance, cannot match all substrates equally well. The result is selection for maximum crypticity on only one of the available substrates. The scale of heterogeneity in these cases ranges from regional contrasts in soil reflectance, which produce matching polymorphisms in desert reptiles (Norris \& Lowe 1964), to variation among species of food plants in a single area of chaparral, where each of the forms of a polymorphic walking stick is maximally abundant on the plant species that it most closely resembles (Sandoval 1994). We refer to this category as specialist polymorphisms. Because diversity is limited by the number of substrate types, specialist polymorphisms generally involve fewer, more distinctive forms, often only green and brown (Dearn 1990, Edmunds 1976, Owen 1980, Poulton 1890, Wente \& Phillips 2003) or dark and light (Kettlewell 1973). In many cases, the dimorphism is genetically determined; in others, it is a polyphenism, a developmental difference in color pattern cued by physical or chemical signals (Edmunds 1976, Greene 1996, Rowell 1971). Because each morph specializes on a particular substrate type, these species may be highly selective in choosing a resting location, actively avoiding nonmatching backgrounds (Edmunds 1976, Owen 1980, Sargent 1981).

Although the structure of the environment helps determine whether a given species will show a specialized or generalized polymorphism, the ecological relationships can be complicated. Catocala relicta is an underwing moth that occurs in at least five distinctive forms (Barnes \& McDunnough 1918). Their favored host plants are white birches and poplars, and when given a choice between oaks and birches, all five forms are differentially attracted to birch trees (Sargent 1981). Three of the morphs are white with dark markings that make them maximally cryptic on younger birch trees and branches. The other two are more uniformly dark, perhaps resembling the texture of the trunks of more mature trees. C. relicta is thus a specialist on a particular substrate type, but occurs in multiple, disparate forms within its specialized niche.

\section{Cognitive Demands of Visual Search}

The rate of information processing in visual systems is subject to inherent limitations. Bottlenecks are encountered at many different levels, but perhaps the clearest illustration of the problem is that the number of sensory receptors in the vertebrate retina is several orders of magnitude higher than the number of axons in the optic nerve. Ganglion cells redundantly encode the essential features of the visual world to minimize the loss of information (Barlow 2001), but even under optimal conditions, the retina transmits data at only about the rate of an Ethernet connection (Koch et al. 2006). Very demanding perceptual tasks, such as detecting camouflaged prey or dealing with a cluttered visual field, take up a lot of bandwidth, so attentional filters are an essential feature of any complex visual system. They are analogous to packet priority schemes in networking software, which allocate bandwidth to specific categories of information in accordance with dynamically changing criteria of their relative importance. Attentional filtering occurs at a variety of different levels in the nervous system and has been a principal focus of research in cognitive psychology for half a century (Parasuraman \& Davies 1984, Pashler 1998). 
Dukas $(2002,2004)$ has argued persuasively for the central importance of attention in behavioral ecology. Competing informational demands require that animals allocate their attentional resources so as to optimize their chances of finding food and avoiding predators (Clark \& Dukas 2003). And because the environment is constantly changing, their attentional allocation must be flexible. Predators must decide where to look for prey, what visual features to focus on, and how long to persist in searching, and they must be able to revise their decisions rapidly on the basis of recent experiences of success and failure. Their transitory expectations are expressed in the form of stimulus filters that determine which prey items will be detected and which will be overlooked. The role of expectancy in the perception of cryptic stimuli is familiar to any naturalist. Croze (1970) cites a particularly evocative description from one of Ian Fleming's novels: "When you are looking for one particular species under water...you have to keep your brain and your eyes focussed for that one individual pattern. The riot of color and movement and the endless variety of light and shadows fight your concentration all the time" (Fleming 1965, p. 312). Note that Fleming emphasized the complexity of the coral reef background, rather than the cryptic coloration of the fish James Bond was seeking, as the primary justification for attentional search.

Von Uexküll (1934) provided the original description of attentional filtering in visual search. In his best-known narrative, he tells of his being accustomed to having water served at mealtime in an earthenware pitcher. One day, the pitcher had been broken, so the servant replaced it with a glass carafe. When von Uexküll came to the table, he looked in vain for the pitcher. He asked for water and was told that it was in its usual place. Only then did the scattered reflections from the carafe assemble themselves into a coherent image. Von Uexküll claimed that the expected stimulus configuration of the pitcher, which he termed a searching image, overrode the perceptual input and prevented him from recognizing the carafe. A striking aspect of all of von Uexküll's searching image anecdotes is that the overlooked object is invariably relatively cryptic, consistent with the view that expectancy is most influential when there are substantial demands on processing capacity. A searching image for an earthenware pitcher might, for example, have little effect on perception of a red ceramic teapot. When the visual system is heavily engaged, an increase in the detectability of one type of stimulus occurs only at the cost of overlooking other, alternative stimuli. Interference with the detection of unexpected stimuli is a characteristic feature of selective attention in humans (Kahneman 1973, Posner \& Snyder 1975) and has consequently been adopted as the operationally defining feature of an attentional process (Mackintosh 1975, Plaisted \& Mackintosh 1995).

For many years, this interference effect proved to be exceedingly difficult to confirm in animal subjects. It has, however, recently been clearly demonstrated by Dukas \& Kamil $(2000,2001)$ with blue jays in an operant apparatus, using a design that compelled the birds to divide their attention either between spatial locations or between stimulus types. The results showed a striking reduction in performance under divided attention conditions, confirming the limitation on information-processing capacity. Unequivocal evidence of interference in selective, as opposed to divided, attention has been harder to obtain because of the large number of potential confounds that must be excluded. In the best controlled studies, however, birds induced to search for particular cryptic stimuli have shown a 
significantly reduced ability to detect alternatives, consistent with an attentional explanation (Blough 1989, 1992; Bond \& Kamil 1999; Bond \& Riley 1991; Langley 1996; Reid \& Shettleworth 1992). Zentall (2005) has reviewed the evidence from a range of different psychological experiments and has concluded that animals are clearly capable of attending to selective aspects of a stimulus display.

\section{Searching Images and Predator Ecology}

The diet of generalist predators is seldom a simple linear function of prey availability. Infrequently encountered prey types tend to be underrepresented in the diet, whereas more abundant ones are consumed in excess. The phenomenon is referred to as switching (Murdoch 1969, Murdoch \& Oaten 1974) or displaying a sigmoid functional response (Holling 1965). Frequency-dependent switching patterns can occur for many reasons, ranging from spatial heterogeneity to the availability of prey refuges to nutritional constraints (Greenwood 1984, Sherratt \& Harvey 1993, Sinervo \& Calsbeek 2006, Staddon 1983). When Tinbergen (1960) studied the predation patterns of insectivorous birds in pine woods, however, he attributed the predators' frequency-dependent prey choices to the effects of searching images. Tinbergen tracked the abundance of various cryptic, arboreal caterpillars and recorded the frequency with which the birds brought them to their nest boxes. There was generally a delay of two to three days between the initial emergence of a prey species and its first appearance in the diet, and Tinbergen inferred that the birds overlooked new prey types because they were not expecting to find them. Only after a set of chance encounters with a newly abundant prey, he hypothesized, did the birds acquire a searching image for them, resulting in a rapid increase in their representation in the diet.

Tinbergen's hypothesis was concerned not with whether searching images existed-whether animals actually used selective attention in visual search - but with how searching images were evoked. To emphasize this distinction, we refer to Tinbergen's hypothesis as perceptual switching. The mechanism is presumably a simple positive feedback. If adoption of a searching image improves the predator's ability to detect cryptic prey items, then prey that are detected more often or more recently will be found more readily than those with which the predator has had less experience. This should produce a disproportionately greater frequency of predation on relatively abundant prey types. And if a searching image for one prey type reduces the ability to detect other, disparate ones, the bias in favor of abundant prey types should be matched by a tendency to overlook rarer forms. The result will be a sigmoid switching function (Figure 3), derived entirely from perceptual dynamics. Clarke (1962) subsequently extended Tinbergen's model, arguing that perceptual switching could account for the maintenance of color polymorphism in cryptic prey species.

Clarke noted that frequency-dependent predation on polymorphic prey should select in favor of rare, deviant phenotypes. With a sigmoid switching function, abundant morphs will be taken disproportionately often, driving down their numbers, while rare ones will be ignored and allowed to increase. As the rarer morphs become more abundant, they will, in turn, become the focus of the predators' interest and will be taken in disproportionate numbers. If mor- 


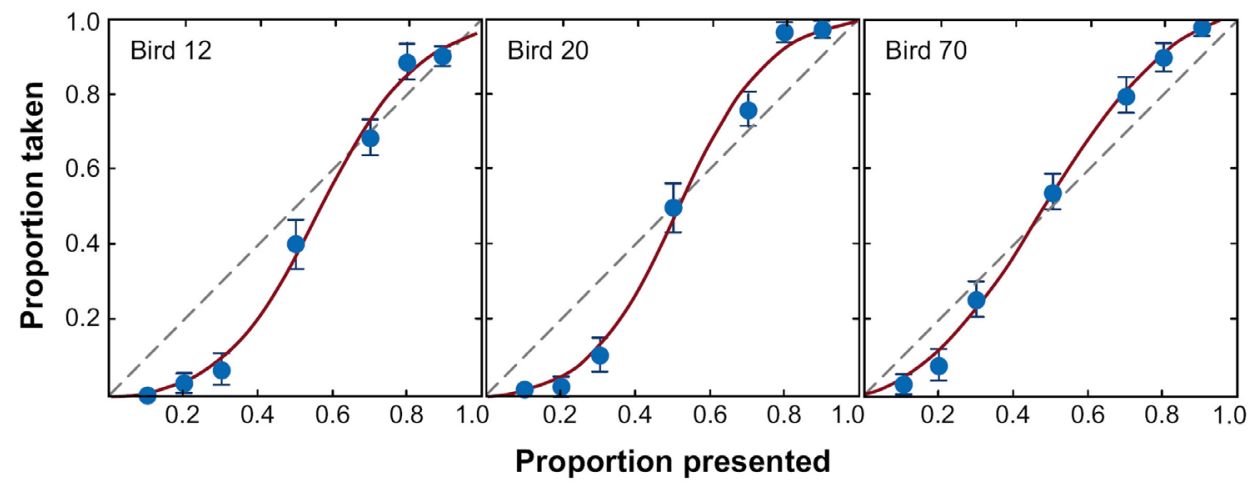

Figure 3. Perceptual switching curves for three pigeons searching for cryptically colored black beans and red wheat on a complex gravel background. The proportion of beans in the sample is shown on the abscissa; the proportion taken by the bird is on the ordinate. Mean values for each treatment condition are plotted with filled circles; hash marks indicate two standard errors. The solid line is a least-squares fit of the raw data to a perceptual switching model; the dashed line indicates the null hypothesis of indifference or lack of selection. Figure adapted with permission from Bond (1983).

tality is mainly a consequence of visual predation, this predation pattern could serve to stabilize the numbers of an array of alternative morphs. Clarke's theoretical mechanism, which he called apostatic selection, was attractive, but it was based on very limited empirical results: Tinbergen's invocation of searching images went well beyond what could legitimately be inferred from his uncontrolled field observations (Croze 1970, Royama 1970). This prompted a contentious literature on whether searching images exist, how they can be experimentally demonstrated, and whether they provide a satisfactory account of the evolution of color polymorphism (Curio 1976, Endler 1991; reviewed in Krebs 1973, Punzalan et al. 2005, Shettleworth et al. 1993).

Validation of the perceptual switching hypothesis seems straightforward, in principle. It only requires, first, that prey types that have been detected more frequently should subsequently be detected more reliably, and second, that when the discriminability of one prey type is maximized, the others should become less detectable. Researchers were slow to realize, however, the number of controls that were required to eliminate other possible interpretations. Many early studies, for example, focused on the initial acquisition of a feeding response to novel prey types (Fullick \& Greenwood 1979, Willis et al. 1980), or on subsequent feeding preferences for familiar prey items (Allen 1974, 1984), or on learning to discriminate a familiar prey in novel, cryptic circumstances (Dawkins 1971a, Lawrence 1985). However, disparities in training or familiarity only induce transitory response biases. They cannot sustain a continuing pattern of perceptual switching (Bond 1983, Langley et al. 1995). A hypothetical predator influenced only by long-term learning would eventually become familiar with all prey in its environment and would consume them in direct proportion to their abundance. For an appropriate test of perceptual switching, predators have to be thoroughly experienced with all prey types prior to beginning experimental trials. 
Other possible sources of frequency-dependent switching also have to be controlled. To avoid diet selection biases, only prey of roughly comparable size and nutritional value should be used (Punzalan et al. 2005). When multiple prey items can be viewed simultaneously, local visual contrasts between items become influential, and response biases reduce the effect of perceptual switching (Allen \& Weale 2005, Bond 1983, Church et al. 1997). The prey thus need to be randomly intermixed and overdispersed, so as to insure that they are encountered sequentially (Bond 1983, Gendron 1982, Getty \& Pulliam 1993). To produce a polymorphism of cryptically colored stimuli, many studies have used heterogeneous backgrounds with corresponding cryptic and conspicuous food items (e.g., Dawkins 1971a, Getty \& Pulliam 1993, Reid \& Shettleworth 1992). Interpretation of the results of these experiments can be complicated, however, as the difference in backgrounds provides an independent cue that can bias the predator's search and increase the variance in prey detection (Bond \& Kamil 2006, Kono et al. 1998, Royama 1970). Finally, the prey items should all be roughly equivalently cryptic on the same substrate (a generalist polymorphism) to maximize analytical sensitivity. Given these constraints, there have been three primary experimental approaches to studying searching images, each of which has a different balance of control and realism: free-choice experiments, sequence analyses, and operant detection tasks.

Much of the literature on searching images and color polymorphism consists of free-choice experiments that provide animals with two or more distinguishable prey types at different relative abundances. If varying the abundances results in a sigmoid switching function, and if other factors have been carefully controlled, this design should in principle provide robust evidence of the dynamics of perceptual switching. For example, Bond (1983) studied captive pigeons that fed from trays containing varying proportions of familiar, natural food grains randomly dispersed on a complex gravel background. To control for the possibility of prior preferences and response biases, the same grain types were displayed on both cryptic and conspicuous backgrounds. The birds all showed significant perceptual switching effects when the grains were cryptic (Figure 3), effects that disappeared when the grains were conspicuous. The response rate was highest on samples containing a single grain type and decreased as the relative proportions approached equality, suggesting a reduction in searching efficiency as a consequence of switching back and forth between food types (Dukas \& Kamil 2000). The occurrence of perceptual switching has been demonstrated in several other free-choice experiments as well (Cooper 1984, Cooper \& Allen 1994, Langley et al. 1995, Reid \& Shettleworth 1992, Tucker 1991). The method produces robust and consistent results, but prey crypticity is difficult to manipulate in a systematic fashion. And because the sequence of prey encounters cannot be controlled, and has seldom even been directly recorded, the results cannot confirm a reduction in the detectability of alternative prey types (Bond 1983, Kamil \& Bond 2006).

If recently experienced prey types become easier to detect, while alternative ones become harder, predators should tend to take prey in homogeneous runs (McNair 1980). Dawkins (1971b) identified this runs effect in studies of chicks 
feeding on colored rice grains and related it to attentional searching. Her design can be carried further, however. Given the underlying dynamics, the time between successive items within a run should be significantly shorter than the time between runs of different prey types. More cryptic prey should also be taken in longer runs and should show longer delays between runs of different types. These predictions have been confirmed in human subjects sorting colored wooden beads (Bond 1982), but the analytical power of sequential analysis has been relatively neglected in free-choice experiments on animals. Dawkins' results did, however, suggest that adoption of a searching image might be induced by presenting cryptic visual stimuli one at a time and manipulating the imposed sequence to produce a run of a particular stimulus type. This rationale transforms visual search for multiple prey types into an operant serial detection task, a standard psychological procedure in which an animal is presented with a succession of visual displays.

Using this design, Pietrewicz \& Kamil $(1977,1979)$ trained blue jays to detect cryptic moths in slide images and found that runs in the imposed stimulus sequence significantly improved the probability both of detecting moths when they were present (positive trials) and of correctly rejecting images without moths (negative trials). No such changes were observed when moths of different types were presented in random sequences, providing strong evidence for improvement in discriminability over successive encounters with the same prey type. Similar results have since been obtained in studies with pigeons, using images of cryptic grains (Bond \& Riley 1991, Langley 1996) or alphanumeric characters (Blough 1989, 1991, 1992), and have been repeatedly confirmed in experiments with blue jays, using artificial stimuli with predetermined levels of crypticity (Bond \& Kamil 1999; Dukas \& Kamil 2000, 2001). Several operant studies have also confirmed the predicted reduction in the detectability of alternative stimuli, under conditions that effectively excluded nonattentional explanations (Blough 1989, 1992; Bond \& Kamil 1999; Bond \& Riley 1991; Langley 1996).

Under controlled experimental conditions, therefore, animals exhibit attentional biases consistent with Tinbergen's hypothesis of perceptual switching. Despite this apparent triumph of the operant approach, however, it is unclear how the results relate to the evolution of color polymorphism in the field (Punzalan et al. 2005). In particular, the ecological and evolutionary effects of perceptual switching depend crucially upon how searching images are deployed. How should predators choose which prey type to attend to at any given moment, how rapidly should they scan their environment, and how long should they persist in searching for a prey type that is no longer abundant? These are questions not of the perceptual mechanism itself, but of the allocation of cognitive resources to make optimal use of the animal's perceptual capabilities (Staddon 1980). Decision processes have been heavily investigated in other areas of foraging behavior, particularly in patch and diet selection (Shettleworth et al. 1993, Stephens \& Krebs 1986). The dynamics of perceptual switching have, as yet, received far less consideration, although a rough outline of the relevant issues can be gathered from the existing literature. 


\section{Dynamics of Perceptual Switching}

The improvement in discriminability resulting from attention is, in part, a function of the demands of the detection task, including the crypticity of the prey, the complexity of the background, and the magnitude of competing attentional requirements. Several authors have assumed that predators alternate between a selective search mode in which they focus exclusively on one prey type and a broader, general mode that is less efficient but receptive to multiple stimulus alternatives (Bond 1983, McNair 1980, 1981). This model is almost certainly an oversimplification. Attentional search is not exclusive, but actually somewhat porous, providing little interference to the detection of more salient, nonattended items (Blough 1992, Bond \& Kamil 1999). Allocation of attentional resources appears to be graded, with longer runs of the same prey type eliciting larger attentional allotments (Dukas \& Ellner 1993, Dukas \& Kamil 2001, Gendron 1986). And there is no evidence of a generally receptive search mode: Animals can locate multiple, disparate, conspicuous items using pre-attentive parallel search mechanisms (Bond \& Kamil 2006, Dukas 2002), but cryptic prey cannot be successfully detected with a nonattentive search (Wolfe 1994, Wolfe et al. 2002). Estimating the economic benefits of particular patterns of attentional allocation will require more extensive research and modeling.

A predator that persists in searching for prey that have become locally depleted might be said to show functional response hysteresis, in that he shifts only gradually between states in response to imposed changes in resource abundance (Getty \& Krebs 1985, Murdoch 1970). How readily apostatic selection can stabilize a prey polymorphism will depend upon the level of hysteresis. A predator that is slow to switch will produce wide fluctuations in relative abundance, increasing the chance of local morph extinctions. The processes that initiate and terminate attentional search are, thus, of major importance in determining the ecological effects of perceptual switching. Searching images are evoked by a contiguous series of detections of the same stimulus item (Blough 1991, 1992; Bond \& Kamil 1999; Kamil \& Bond 2006). The number of required detections seems invariably more than one, but generally fewer than five or six (Bond \& Kamil 1999, Bond \& Riley 1991, Croze 1970, Pietrewicz \& Kamil 1979). Depending upon the species, time intervals between detections can also have a significant impact. Attentional search can be elicited in blue jays even with negative trials interspersed among the positives in a run (Bond \& Kamil 1999, Pietrewicz \& Kamil 1979), but pigeons require contiguous blocks of positive trials (Bond \& Riley 1991). This may account for the strong effects of intertrial intervals in visual search in pigeons (Plaisted 1997), effects that could not be replicated using blue jays (Bond \& Kamil 1999).

The reduction in attention to a prey type that has declined in numbers and become unprofitable has been considered as an analog to the patch-departure problem in optimal foraging theory. Several authors have modeled this decision with a giving-up time that determines a predator's persistence in searching for a specific prey type (Bond 1983, Croze 1970, Dukas \& Ellner 1993). Using this model, Bond (1983) suggested that pigeons searching for two disparate cryptic grains could be switching their attentional focus in response to as little as $100 \mathrm{~ms}$ of unrewarded 
searching. In a later pigeon study, however, Langley et al. (1995) evoked a searching image with one grain type and subsequently tested it using equal numbers of both grains. A delay of $30 \mathrm{~s}$ between evocation and testing had no effect, but when the delay was increased to $3 \mathrm{~min}$, the birds showed a decreased responsiveness to the attended grain type. Searching images can thus be discarded if a sufficient delay is imposed, but a simple temporal threshold does not appear to capture the dynamics of the switching process. It is possible that searching images are seldom actually relinquished, but, rather, are gradually attenuated when prey detections become infrequent, allowing alternative stimuli to be more readily noticed. By this reasoning, perceptual switching could be modeled as a graded fluctuation among alternative attentional states (Falmagne 1965, Maljkovic \& Martini 2005, Schweickert 1993). This model would help to explain why strong searching image effects can be observed even when prey appearance is continuously variable (Bond \& Kamil 2002, 2006).

In addition to perceptual factors, the dynamics of perceptual switching are strongly influenced by the distribution of searching effort in space and time, measured either as the rate of movement through the habitat (Gendron 1986; Gendron \& Staddon 1983, 1984) or as the duration of scanning at successive discrete locations (Bond \& Riley 1991, Endler 1991, Getty \& Pulliam 1991). This is an essential aspect of visual search, as it regulates and focuses the flow of novel visual information. Limiting the search rate produces a spatial allocation of attentional resources that complements the discriminability (Dukas 2004, Getty et al. 1987) or the probability (Wolfe et al. 2005, 2007) of particular visual stimuli. When Gendron \& Staddon $(1983,1984)$ modeled the effects of varying the search rate, they found an inverse relationship between search rate and prey detectability. Conspicuous stimuli are reliably detected at greater distances, so they can be searched for at greater speeds. Cryptic stimuli, in contrast, require the predator to slow down and scan its surroundings more thoroughly. Subsequent studies have substantially confirmed this speed/accuracy trade-off in prey detection (Gendron 1986, Getty et al. 1987) and have clarified the complementary roles of perceptual and tactical constraints in the allocation of search effort (Getty \& Pulliam 1991, 1993).

The complementarity of visual and spatial attention makes disentangling their relative influences a significant challenge, particularly in free-choice experiments. Guilford \& Dawkins (1987) noted that predators that optimized their search rates would have asymmetrical effects on mixtures of prey types. Relatively cryptic prey would be detected less frequently than expected, whereas more conspicuous items would be found more readily. In some circumstances, these effects could be confused with perceptual switching. Several studies have since confirmed the occurrence of perceptual switching when search rates are either controlled or irrelevant (reviewed in Endler 1991, Kamil \& Bond 2006, Shettleworth et al. 1993) or have demonstrated simultaneous, independent effects of both search rate and searching images (Bond \& Riley 1991, Getty et al. 1987). Asymmetrical results have been pervasive, however, in studies that used small numbers of cryptic prey types. Attention to relatively conspicuous stimuli invariably reduces the detection of more cryptic alternatives, but attention to relatively cryptic stimuli generally has less of an effect (Blough 1989, 1992; Bond \& Kamil 1999; Bond \& Riley 
1991; Reid \& Shettleworth 1992). Simulation results suggest that this asymmetry may be an inherent consequence of the optimal allocation of attention, a manifestation of the compromise between speed and accuracy (Bond \& Riley 1991).

\section{Apostatic Selection and Balanced Polymorphism}

The development and maintenance of color polymorphism is one of the great persisting issues in ecology and evolution, in part because it is often unclear whether natural polymorphisms constitute a stable array of forms maintained by frequency-dependent predation (Oxford \& Gillespie 1998), or just a transient mix of alleles resulting from genetic drift and dispersal (Fisher 1930, Ford 1975). Many natural color polymorphisms, when closely examined, can be attributed to nonselective processes, such as regional selection combined with migration and dispersal (Dearn 1984, King \& Lawson 1995, Reillo \& Wise 1988), or genetic drift and local population bottlenecks (Brakefield 1990). Even the world's most intensively studied polymorphism, that of the Cepaea land snails, is sustained in part by migration, drift, and founder effects (Bellido et al. 2002, Cook 1998).

Observational studies of color polymorphism that have successfully excluded nonselective explanations commonly invoke apostatic selection by visual predators as the likely agency (e.g., Atkinson \& Warwick 1983, Jormalainen et al. 1995, Oxford \& Gillespie 1998). These inferences may well be correct, but they often only reflect the absence of evidence to the contrary. Allen and his colleagues have conducted numerous experiments in which colored baits are broadcast in the field and fed on by wild birds (reviewed in Allen 1988, Allen \& Weale 2005, Cooper \& Allen 1994). Their results are consistent with apostatic selection, but because they generally did not control which birds had access to the baits and did not record the sequence and timing of items taken by individual birds, the nature of the selective mechanism is open to alternative interpretations. Translocation experiments on natural polymorphisms (e.g., Cox \& Cox 1974, Halkka et al. 1975, Sandoval 1994) have provided compelling field evidence of stabilizing selection in specialist polymorphisms. Field studies that have gone further and manipulated relative morph abundances directly, as in Olendorf et al.'s (2006) work on guppies or Reid's (1987) study of mangrove snails, have demonstrated apostatic selection in favor of rare color morphs. Even in these cases, however, the selective mechanism has been inferred from the pattern of prey survival rather than from observations of predatory behavior. Whether selection has resulted from perceptual switching in individual predators has not been established.

The only direct evaluation of the selective effects of visual predation on prey polymorphism has been conducted by Bond \& Kamil $(1998,2002,2006)$ in a laboratory system that allowed for complex interactions between the abundance, the appearance, and the detection of prey. Their methodology, based on operant studies of searching images, involved presenting captive blue jays with digital moths imbedded in complex textured backgrounds. An initial study with this preparation (Bond \& Kamil 1999) showed clear evidence of perceptual switching: During runs of a single moth type, discriminability improved for the focal moth and declined for alternative, disparate forms. The experimental rationale 
was thus the inverse of a typical field study. First, they developed a system in which perceptual switching was known to be displayed, and then they tested it for indications of apostatic selection.

To determine whether perceptual switching could maintain a balanced polymorphism, Bond \& Kamil (1998) created a digital moth population with equal numbers of each of three distinctive morphs and exposed them to predation by a squad of blue jays. At the end of each day's session, moths that had been detected were considered killed and were removed from the population. Those that were overlooked were cloned in proportion to their relative numbers, bringing the population up to its previous level for the following day. Over the course of 50 generations, morph abundances rapidly achieved a characteristic oscillatory equilibrium that included all three morphs and that was independent of their initial population levels. Additional analyses demonstrated that the equilibrium was a result of apostatic selection, a positive correlation between prey abundance and detectability. The experiment confirmed that perceptual switching can produce apostatic selection and can thereby maintain a balanced polymorphism.

In the second phase of their research, Bond \& Kamil (2002) eliminated the constraint of fixed asexual morphs. Moth phenotypes were specified by haploid genomes that evolved over successive generations in accordance with a genetic algorithm. Moths that the blue jays overlooked or were slow to detect were more likely to be chosen to breed. Under this regime, initially monomorphic parental populations evolved through 100 progeny generations without further experimental intervention. To test whether crypticity and phenotypic variance were selected for in the experimental lines, the results were contrasted with those from two sets of control lineages, one resulting only from genetic drift and the other using frequency-independent directional selection for increased crypticity. In each experimental lineage, the moths became significantly harder to detect, but the experimental lines also evolved significantly greater phenotypic variance than the frequency-independent controls (Figure 4). This indicated that apostatic selection could actively promote the evolution of multiple disparate forms in a previously monomorphic population.

The backgrounds used in this study were fine grained and relatively homogenous, resembling coarse gravel. Selection on this substrate resulted in massive, generalist polymorphisms, similar to those in beach clams (Whiteley et al. 1997). Only in a later study using heterogeneous backgrounds did Bond \& Kamil observe any signs of specialist polymorphisms (Bond \& Kamil 2006). This was an attractive finding, as it was consistent both with ecological theory of the effects of coarse-grained habitats (Kisdi 2001, Levins 1968, Merilaita et al. 1999) and with the known association between patchy habitats and genetic polymorphism (Hedrick 2006). Even in their most heterogeneous treatments, however, Bond \& Kamil still did not obtain a classical, discrete polymorphism of a handful of disparate forms. Some additional causal factors appear to be operating in natural environments to limit morph diversity, perhaps involving more extreme contrasts between patch types, biases among prey in their choice of resting locations, or disruptive selection against hybrid individuals (Hedrick 2006, Maynard Smith 1962).

Analysis of the pattern of detection as a function of trial sequence in these experiments showed that blue jays consistently overlooked atypical cryptic moths, 


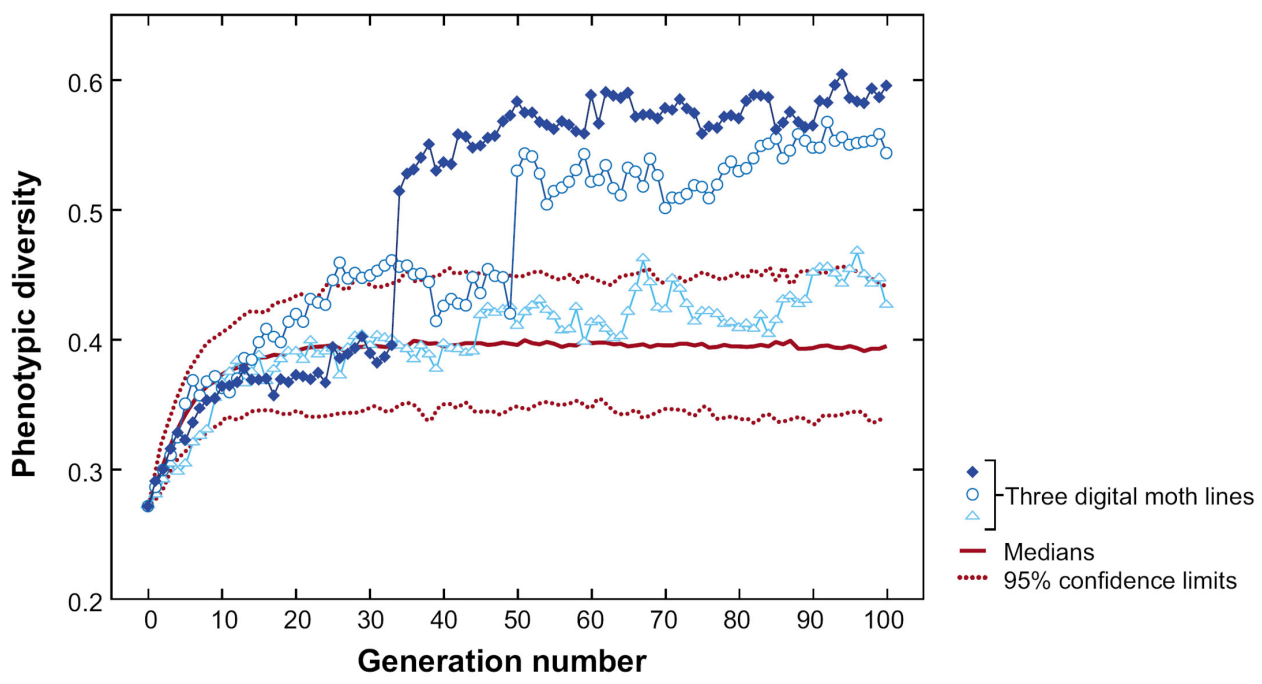

Figure 4. Changes in phenotypic variance of a population of digital moths in three experimental lines (plotted in blue with triangles, circles, and diamonds, respectively) under selection by captive blue jays. Experimental results are contrasted to the phenotypic variance in 200 replicate control lines that underwent only frequency-independent selection for crypticity. Medians and $95 \%$ confidence limits for the control lines are shown in red. Phenotypic variance increased to some degree in all treatments, but the increase was significantly greater in the experimental lines than in the controls. Two of the experimental lines exhibited an abrupt shift to a higher level of phenotypic variance at some point in the course of selection trials, apparently produced by the explosive spread of mutant regulatory genes. Figure adapted with permission from Bond \& Kamil (2002).

confirming perceptual switching as the primary agency of selection. This is a somewhat puzzling finding in that the digital moth populations were extraordinarily variable, far more so than the stimuli used in any previous study of searching images. This diversity might be expected to reduce the birds' tendency to attend to particular stimulus features, but in fact it had the opposite effect. Perceptual switching was shown at some crypticity levels in all experimental treatments, but it was spectacularly evident among moderately cryptic moths on very complex backgrounds (Figure 5, plot d2). Searching images did not show as large an effect with highly cryptic moths on these backgrounds (Figure 5, plot d3). Presumably, the limitation on the number of features that can reliably distinguish these stimuli from the background restricts the benefits of visual attention (Bond 1983). However, the birds were clearly still conducting a serial attentional search, even in these circumstances, because highly cryptic, atypical moths were almost completely overlooked.

The results of these virtual ecology studies thus bear an encouraging resemblance to the ecological associations of natural polymorphisms. Combined with the findings of other experiments on attentional search, perceptual switching, and 


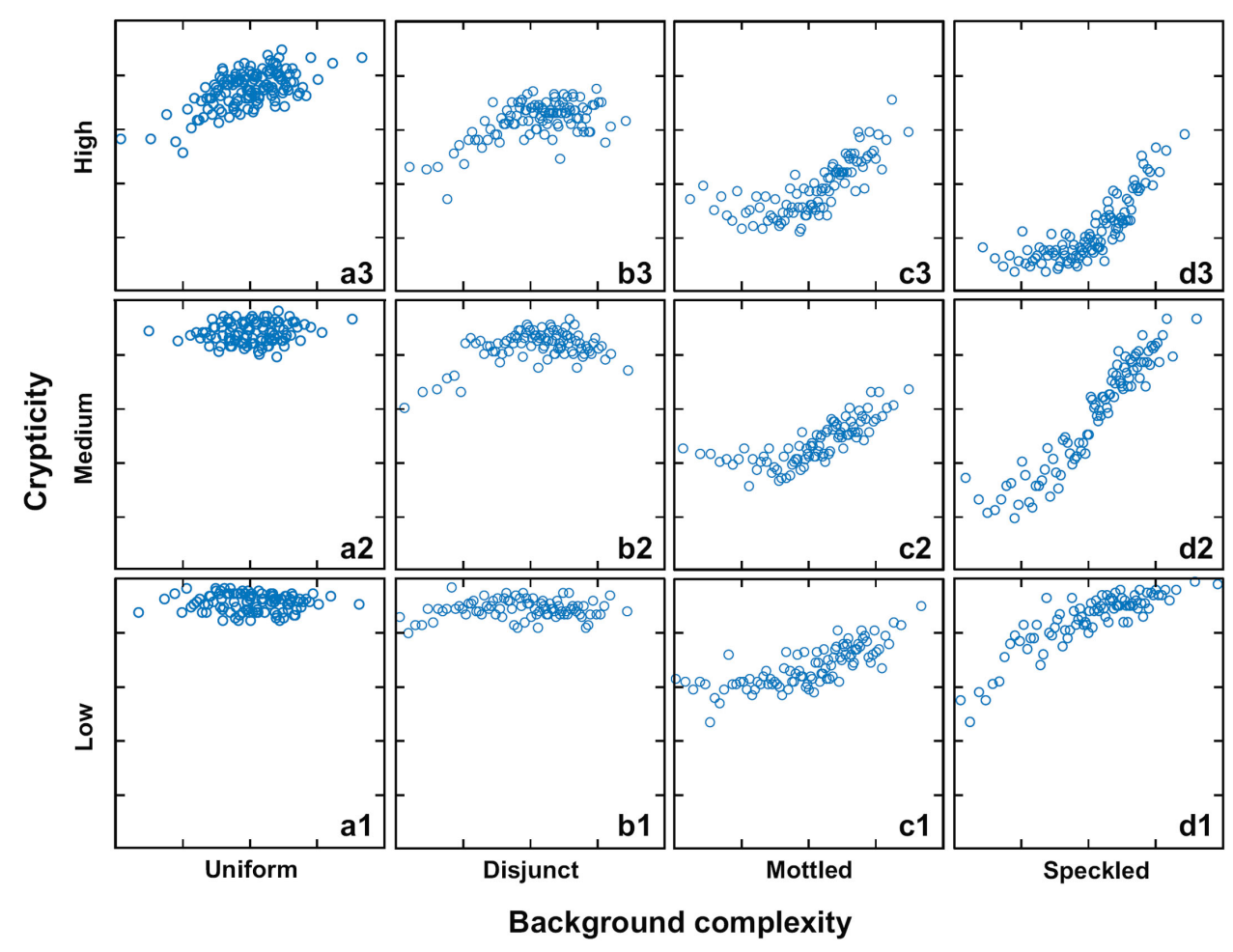

Figure 5. Each panel displays the detection accuracy in blocks of 100 trials (on the ordinate, ranging from $0 \%$ to $100 \%$ ) as a function of the morphological similarity between the current digital moth and the previous correctly detected one (on the abscissa). In these plots, apostatic selection appears as a positive regression slope, indicating higher accuracies for moths that were more similar to previously detected targets. Moth crypticity increases from the bottom to the top panel, dividing the range of crypticity indices within each treatment into percentile groupings: low ( 0 to $33 \mathrm{rd}$ ), medium (34th to 66th), and high (67th to 100th). Visual complexity increases from the left panels $(\mathrm{al}-\mathrm{a} 3)$ to the right ones $(\mathrm{dl}-\mathrm{d} 3)$, ranging from the uniform texture used in Bond \& $\mathrm{Ka}$ mil (2002) to the three heterogeneity treatments used in Bond \& Kamil (2006). Significant levels of apostatic selection were displayed in high crypticity moths on the Uniform and Disjunct backgrounds (a3 and b3) and in all crypticity groupings on the Mottled and Speckled backgrounds (cl$c 3$ and $d \mathrm{I}-\mathrm{d} 3)$.

apostatic selection, the literature now provides a persuasive and well-supported causal narrative. Punzalan et al. (2005) remain unconvinced, asserting that there is no unequivocal evidence of a role for searching images in sustaining any natural polymorphism. Their insistence on ecological realism seems overly stringent, however. Given the requisite level of experimental control, it is difficult to envision any similarly complex behavioral mechanism that could be definitively demonstrated under field conditions. The classical field studies of visual search, such as Croze's (1970) experiments on carrion crows and Murton's (1971) investiga- 
tions of wood pigeons, make clear that foraging behavior in the wild is a rich and complex phenomenon, one that resists our desire for unequivocal answers. Using established methods and analytical techniques, however, it should be possible to design a well-controlled free-choice experiment that would definitively demonstrate the occurrence of apostatic selection among the forms of a naturally polymorphic prey species.

To regulate and record interactions between predators and prey, one would need to conduct an aviary study, similar to Getty \& Pulliam's (1993) elegant work on the foraging behavior of captive sparrows. Getty \& Pulliam placed cryptic seeds at predetermined random locations on natural soil backgrounds, released single white-throated sparrows to search for them, and videotaped all movements and detection successes of the birds. The authors then analyzed the tapes using random search models developed for naval reconnaissance, which allowed them to determine not just which seeds were found by the birds, but which ones were overlooked. Although Getty \& Pulliam (1993) were not concerned with searching image effects, it would be possible to use their design with, perhaps, a random array of Cepaea land snails on a complex natural background at a range of relative and absolute abundances. Other species would certainly work as well, but predation on Cepaea has been well researched in the field (Bantock \& Bayley 1973, Bantock et al. 1975) and in aviaries (Tucker 1991), and the snail shells can readily be converted to motionless stimuli (Allen \& Weale 2005, Harvey et al. 1975). To control for response bias effects, tests would also be run on a similarly structured alternative substrate on which the shells were relatively conspicuous. Such research would constitute a valuable step in linking established laboratory results to the evolutionary dynamics of natural color polymorphisms.

\section{Goals for Future Work}

Experiments have confirmed the role of selective attention in the search for cryptic prey, have shown that predators switch among attentional states in response to short-term changes in prey detection, and have demonstrated that perceptual switching can promote and maintain cryptic color polymorphism. A great deal still remains to be done, however. Whether perceptual switching plays a role in maintaining natural polymorphisms depends upon the predator's allocation of cognitive resources in space and time, and this crucial aspect of foraging dynamics has been little explored. The structure and pattern of the background has direct effects on visual search and prey detectability that probably constrain the evolution of prey phenotypes in ways that we do not yet understand. And finally, apostatic selection has been shown to produce increases in phenotypic variance, but has yet to generate a characteristic polymorphism of a limited number of distinctive forms. There are clearly major components in the biology of polymorphism that have yet to be included in an explanatory account. We have only begun to explore the richness and complexity of visual search, predator cognition, and their evolutionary effects on prey coloration. 


\section{Acknowledgments}

Production of this manuscript was supported in part by grants from the National Science Foundation (IOB-0234441) and the National Institutes for Mental Health (R01-MH068426).

\section{Literature Cited}

Allen JA. 1974. Further evidence for apostatic selection by wild passerine birds: training experiments. Heredity 33:36I-72

Allen JA. 1984. Wild birds prefer to eat the more familiar of artificial morphs that are similar in colour. Heredity 53:705-15

Allen JA. 1988. Frequency-dependent selection by predators. Philos. Trans. R. Soc. London Ser. B 319:485-503

Allen JA, Weale ME. 2005. Anti-apostatic selection by wild birds on quasi-natural morphs of the land snail Cepaea hortensis: a generalised linear mixed models approach. Oikos 108:335-43

Atkinson WD, Warwick T. 1983. The role of selection in the colour polymorphism of Littorina rudis Maton and Littorina arcana Hannaford-Ellis (Prosobranchia: Littorinidae). Biol. J. Linn. Soc. 20:|37-5।

Bantock CR, Bayley JA. 1973. Visual selection for shell size in Cepaea (Held.). J. Anim. Ecol. 42:247-61

Bantock CR, Bayley JA, Harvey PH. 1975. Simultaneous selective predation on two features of a mixed sibling species population. Evolution 29:636-49

Barlow H. 200I. Redundancy reduction revisited. Network 12:24I-53

Barnes W, McDunnough J. 1918. Illustrations of the North American species of the genus Catocala. Mem. Am. Mus. Nat. Hist., New Ser.Ver. 3, Pt. I. New York:Am. Mus. Nat. Hist.

Bellido A, Madec L, Arnaud J-F, Guiller A. 2002. Spatial structure of shell polychromatism in populations of Cepaea nemoralis: new techniques for an old debate. Heredity 88:75-82

Blough PM. 1989. Attentional priming and visual search in pigeons. J. Exp. Psychol. Anim. B 15:358-65

Blough PM. 1991. Selective attention and search images in pigeons. J. Exp. Psychol. Anim. B 17:292-98

Blough PM. 1992. Detectability and choice during visual search: joint effects of sequential priming and discriminability. Anim. Learn. Behav. 20:293-300

Bond AB. 1982. The bead game: response strategies in free assortment. Hum. Factors 24: $101-10$

Bond $A B$. 1983. Visual search and selection of natural stimuli in the pigeon: the attention threshold hypothesis. J. Exp. Psychol. Anim. B 9:292-306

Bond AB, Kamil AC. 1998. Apostatic selection by blue jays produces balanced polymorphism in virtual prey. Nature 395:594-96

Bond AB, Kamil AC. 1999. Searching image in blue jays: facilitation and interference in sequential priming. Anim. Learn. Behav. 27:46I-7I 
Bond AB, Kamil AC. 2002. Visual predators select for crypticity and polymorphism in virtual prey. Nature 415:609-I4

Bond AB, Kamil AC. 2006. Spatial heterogeneity, predator cognition, and the evolution of color polymorphism in virtual prey. Proc. Natl.Acad. Sci. USA 103:3214-19

Bond AB, Riley DA. 199I. Searching image in the pigeon: a test of three hypothetical mechanisms. Ethology 87:203-24

Bonte D, Maelfait JP. 2004. Colour variation and crypsis in relation to habitat selection in the males of the crab spider Xysticus sabulosus (Hahn, 1832) (Araneae: Thomisidae). Belg.J. Zool. 134:3-7

Brakefield PM. 1990. Genetic drift and patterns of diversity among colour-polymorphic populations of the homopteran Philaenus spumarius in an island archipelago. Biol. J. Linn. Soc. 39:219-37

Cain AJ, Sheppard PM. 1954. Natural selection in Cepaea. Genetics 39:89-II6

Castner JL, Nickle DA. 1995. Intraspecific color polymorphism in leaf-mimicking katydids (Orthoptera:Terrigoniidae: Pseudophyllinae: Pterochrozini). J. Orthop. Res. 4:99-103

Church SC, Jowers M, Allen JA. 1997. Does prey dispersion affect frequency-dependent selection by wild birds? Oecologia I I I:292-96

Clark CW, Dukas R. 2003. The behavioral ecology of a cognitive constraint: limited attention. Behav. Ecol. |4:15|-56

Clarke BC. 1962. Balanced polymorphism and the diversity of sympatric species. In Taxonomy and Geography, ed. D Nichols, pp. 47-70. Oxford: Syst. Assoc.

Clarke BC, Arthur W, Horseley DT, Parkin DT. 1978. Genetic variation and natural selection in pulmonate snails. In The Pulmonates. Vol. 2A: Systematics, Evolution, and Ecology, ed. V Fretter, J Peake, pp. 220-70. New York:Academic

Common IFB. 1954. A study of the ecology of the adult bogong moth, Agrotis infusa (Boisd.) (Lepidoptera: Noctuidae), with special reference to its behaviour during migration and aestivation. Aust.J. Zool. 2:223-63

Connolly RM, Melville AJ, Keesing JK. 2002. Abundance, movement and individual identification of leafy seadragons. Mar. Freshw. Res. 53:777-80

Cook LM. 1998. A two-stage model for Cepaea polymorphism. Philos. Trans. R. Soc. London Ser. B 353:1577-93

Cooper JM. 1984. Apostatic selection on prey that match the background. Biol. J. Linn. Soc. 23:22I-28

Cooper JM, Allen JA. 1994. Selection by wild birds on artificial dimorphic prey on varied backgrounds. Biol.J. Linn. Soc. 51:433-46

Cott HB. 1957. Adaptive Coloration in Animals. London: Methuen. 508 pp.

Cox GW, Cox DG. 1974. Substrate color matching in the grasshopper Circotettix rabula. Great Basin Nat. 34:60-70

Croze H. 1970. Searching Image in Carrion Crows. Berlin: Paul Parey. 85 pp.

Curio E. 1976. The Ethology of Predation. Berlin: Springer-Verlag. 250 pp.

Dawkins M. I97la. Perceptual changes in chicks: another look at the "search image" concept. Anim. Behav. 19:566-74

Dawkins M. 197Ib. Shifts of "attention" in chicks during feeding. Anim. Behav. 19:575-82 
de Ruiter L. 1952. Some experiments on the camouflage of stick caterpillars. Behaviour 4:222-32

Dearn JM. 1984. Colour pattern polymorphism in the grasshopper Phaulacridium vittatum I. Geographic variation in Victoria and evidence of habitat association. Aust.J. Zool. 32:239-49

Dearn JM. 1990. Color pattern polymorphism. In Biology of Grasshoppers, ed. RF Chapman, A Joern, pp. 517-49. New York:Wiley

Devin S, Bollache L, Beisle J-N, Moreteau J-C, Perrot-Minnot M-J. 2004. Pigmentation polymorphism in the invasive amphipod Dikerogammarus villosus: some insights into its maintenance.J. Zool. 264:391-97

Dukas R. 2002. Behavioural and ecological consequences of limited attention. Philos. Trans. R. Soc. London Ser. B 357:1539-47

Dukas R. 2004. Causes and consequences of limited attention. Brain Behav. Evol. 63:197-210

Dukas R, Ellner S. 1993. Information processing and prey detection. Ecology 74: I337-46

Dukas R, Kamil AC. 2000. The cost of limited attention in blue jays. Behav. Ecol. I I:502-6

Dukas R, Kamil AC. 200I. Limited attention: the constraint underlying search image. Behav. Ecol. 12:192-99

Edmunds M. 1974. Defense in Animals. Burnt Mill, UK: Longman. 357 pp.

Edmunds M. 1976. The defensive behaviour of Ghanaian praying mantids with a discussion of territoriality. Zool. J. Linn. Soc. 58: I-37

Edmunds M. 1990. The evolution of cryptic coloration. In Insect Defenses: Adaptive Mechanisms and Strategies of Prey and Predators, ed. DL Evans, JO Schmidt, Pp. 3-2I. Albany, NY: SUNY Press

Endler JA. 1978. A predator's view of animal color patterns. Evol. Biol. I I:3 I 9-64

Endler JA. 198I. An overview of the relationships between mimicry and crypsis. Biol.J. Linn. Soc. 16:25-3|

Endler JA. 1984. Progressive background matching in moths, and a quantitative measure of crypsis. Biol.J. Linn. Soc. 22:|87-23।

Endler JA. 1991. Interactions between predators and prey. In Behavior Ecology, ed. JR Krebs, NB Davies, Pp. 169-96. London: Blackwell

Falmagne JC. 1965. Stochastic models for choice reaction time with applications to experimental results. J. Math. Psychol. 2:77-124

Fisher RA. 1930. The Genetical Theory of Natural Seleciton. Oxford: Clarendon. 272 pp.

Fleming I. 1965. Bonded Fleming:A James Bond Omnibus. New York:Viking. 439 Pp.

Ford EB. 1975. Ecological Genetics. London: Chapman \& Hall. 442 pp.

Fullick TG, Greenwood JJD. 1979. Frequency-dependent food selection in relation to two models. Am. Nat. I I 3:762-65

Gendron RP. 1982. The foraging behavior of bobwhite quail searching for cryptic prey. PhD thesis. Duke Univ. I I 8 pp.

Gendron RP. 1986. Searching for cryptic prey: evidence for optimal search rates and the formation of search images in quail. Anim. Behav. 34:898-912 
Gendron RP, Staddon JER. 1983. Searching for cryptic prey: the effect of search rate. Am. Nat. 121:172-86

Gendron RP, Staddon JER. 1984.A laboratory simulation of foraging behavior: the effect of search rate on the probability of detecting prey. Am. Nat. 124:407-I5

Getty T, Kamil AC, Real PG. 1987. Signal detection theory and foraging for cryptic or mimetic prey. In Foraging Behavior, ed. AC Kamil, JR Krebs, HR Pulliam, pp. 525-49. New York: Plenum

Getty T, Krebs JR. 1985. Lagging partial preferences for cryptic prey: a signal detection analysis of great tit foraging. Am. Nat. 125:39-60

Getty T, Pulliam HR. 199I. Random prey detection with pause-travel search. Am. Nat. 138:1459-77

Getty T, Pulliam HR. 1993. Search and prey detection by foraging sparrows. Ecology 74:734-42

Greene E. 1996. Effect of light quality and larval diet on morph induction in the polymorphic caterpillar Nemoria arizonaria (Lepidoptera: Geometridae). Biol. J. Linn. Soc. 58:277-85

Greenwood JJD. 1984. The functional basis of frequency-dependent food selection. Biol. J. Linn. Soc. 23:177-99

Guilford T, Dawkins MS. 1987. Search images not proven: a reappraisal of recent evidence. Anim. Behav. 35:1838-45

Halkka O, Halkka L. 1990. Population genetics of the polymorphic meadow spittlebug, Philaenus spumarius (L.). Evol. Biol. 24:|49-9|

Halkka O, Halkka L, Raatikainen M. 1975. Transfer of individuals as a means of investigating natural selection in operation. Heredity 51:581-606

Handford M. 1987. Where's Waldo? Boston: Little, Brown. 27 pp.

Hargeby A, Johansson J, Ahnesjo J. 2004. Habitat-specific pigmentation in a freshwater isopod: adaptive evolution over a small spatiotemporal scale. Evolution 58:81-94

Harvey PH, Birley N, Blackstock TH. 1975. The effect of experience on the selective behaviour of song thrushes feeding on artificial populations of Cepaea (Held). Genetica 45:211-16

Hedrick PW. 2006. Genetic polymorphism in heterogeneous environments: the age of genomics. Annu. Rev. Ecol. Evol. Syst. 37:67-93

Holling CS. 1965. The functional response of predators to prey density and its role in mimicry and population regulation. Mem. Entomol. Soc. Can. 45: I-60

Janzen DH. 1984. Two ways to be a tropical big moth: Santa Rosa saturniids and sphingids. Oxf. Surv. Evol. Biol. I:85-140

Jormalainen V, Merilaita S, Tuomi J. 1995. Differential predation on sexes affects colour polymorphism of the isopod Idotea baltica (Pallas). Biol.J. Linn. Soc. 55:45-68

Kahneman D. 1973. Attention and Effort. Englewood Cliffs, NJ: Prentice-Hall. 246 pp.

Kamil AC, Bond AB. 200I. The evolution of virtual ecology. In Model Systems in Behavioral Ecology, ed. LA Dugatkin, pp. 288-3 I0. Princeton, NJ: Princeton Univ. Press 
Kamil AC, Bond AB. 2006. Selective attention, priming, and foraging behavior. In Comparative Cognition: Experimental Explorations of Animal Intelligence, ed. EA Wasserman, TR Zentall. Oxford: Oxford Univ. Press.

Kettlewell HBD. 1973. The Evolution of Melanism. Oxford: Clarendon. 423 Pp.

King RB, Lawson R. 1995. Color pattern variation in Lake Erie water snakes: the role of gene flow. Evolution 47:1819-33

Kisdi E. 200I. Long-term adaptive diversity in Levene-type models. Evol. Ecol. Res. 3:72I-27

Koch K, McLean J, Segev R, Freed MA, Berry MJl, et al. 2006. How much the eye tells the brain. Curr. Biol. I6:I428-34

Kono H, Reid PJ, Kamil AC. 1998. The effect of background cuing on prey detection. Anim. Behav. 56:963-72

Krebs JR. 1973. Behavioral aspects of predation. In Perspectives in Ethology, ed. PPG Bateson, PH Klopfer. New York: Plenum

Langley CM. 1996. Search images: selective attention to specific visual features. J. Exp. Psychol.Anim. B. 22:152-63

Langley CM, Riley DA, Bond AB, Goel N. 1995. Visual search for natural grains in pigeons: search images and selective attention. J. Exp. Psychol.Anim. B. 22:|39-5 |

Lawrence ES. 1985. Evidence for search image in blackbirds (Turdus merula L.): Short-term learning. Anim. Behav. 33:929-37

Levins R. 1968. Evolution in Changing Environments. Princeton, NJ: Princeton Univ. Press. 120 Pp.

Mackintosh NJ. 1975. A theory of attention: variations in the associability of stimuli with reinforcement. Psychol. Rev. 82:276-98

Maljkovic V, Martini P. 2005. Implicit short-term memory and event frequency effects in visual search. Vis. Res. 45:2831-46

Maynard Smith J.1962. Disruptive selection, polymorphism and sympatric speciation. Nature 195:60-62

McNair JN. 1980. A stochastic foraging model with predator training effects: I. Functional response, switching, and run lengths. Theor. Popul. Biol. 17:141-66

McNair JN. 198I. A stochastic foraging model with predator training effects: II. Optimal diets. Theor. Popul. Biol. 19:147-62

Merilaita S. 2003. Visual background complexity facilitates the evolution of camouflage. Evolution 57: 1248-54

Merilaita S, Lind J. 2005. Background-matching and disruptive coloration, and the evolution of cryptic coloration. Proc. R. Soc. London Ser. B 272:665-70

Merilaita S, Lyytinen A, Mappes J. 200I. Selection for cryptic coloration in a visually heterogeneous habitat. Proc. R. Soc. London Ser. B 268: 1925-29

Merilaita S, Tuomi J, Jormalainen V. 1999. Optimization of cryptic coloration in heterogeneous habitats. Biol.J. Linn. Soc. 67:|5|-61

Moment GB. 1962. Reflexive selection: a possible answer to an old puzzle. Science 136:262-63 
Murdoch WW. 1969. Switching in general predators: experiments on predator specificity and stability of prey populations. Ecol. Monogr. 39:335-54

Murdoch WW. 1970. Population regulation and population inertia. Ecology 5 1:497-502

Murdoch WW, Oaten A. 1974. Predation and population stability. Adv. Ecol. Res. 9: I-I31

Murton RK. 197I. The significance of a specific search image in the feeding behaviour of the wood-pigeon. Behaviour 40:10-42

Nabours RK, Larson I, Hartwig N. 1933. Inheritance of color patterns in the grouse locust Acrydium arenosum Burmeister (Tettigidae). Genetics |8: I59-7|

Norris KS, Lowe $\mathrm{CH}$. 1964. An analysis of background color-matching in amphibians and reptiles. Ecology 45:565-80

Olendorf R, Rodd FH, Punzalan D, Houde AE, Hurt C, et al. 2006. Frequency-dependent survival in natural guppy populations. Nature 44I:633-36

Owen DF. 1980. Camouflage and Mimicry. Chicago: Univ. Chicago Press. 158 pp.

Oxford GS, Gillespie RG. 1998. Evolution and ecology of spider coloration. Annu. Rev. Entomol. 43:619-43 [Abstract]

Parasuraman R, Davies DR. 1984. Varieties of Attention. New York:Academic. 554 pp.

Pashler HE. 1998. The Psychology of Attention. Mahwah, NJ: Lawrence Erlbaum. 494 pp.

Pietrewicz AT, Kamil AC. 1 977.Visual detection of cryptic prey by blue jays (Cyanocitta cristata). Science 195:580-82

Pietrewicz AT, Kamil AC. 1979. Search image formation in the blue jay (Cyanocitta cristata). Science 204:1332-33

Plaisted K. 1997. The effect of interstimulus interval on the discrimination of cryptic targets. J. Exp. Psychol. Anim. B. 23:248-59

Plaisted KC, Mackintosh NJ. 1995. Visual search for cryptic stimuli in pigeons: implications for the search image and search rate hypotheses. Anim. Behav. 50:1219-32

Popham EJ. 194I.The variation in the colour of certain species of Arctorcorisa (Hemiptera, Corixidae) and its significance. Proc. Zool. Soc. London Ser. A I I I:135-72

Posner MI, Snyder CRR. 1975. Facilitation and inhibition in the processing of signals. In Attention and Performance, ed. PM Rabbitt, S Dornic, Pp. 669-82. San Diego, CA: Academic

Poulton EB. 1890. The Colours of Animals:Their Meaning and Use, Especially Considered in the Case of Insects. New York:Appleton. 360 pp.

Punzalan D, Rodd FH, Hughes KA. 2005. Perceptual processes and the maintenance of polymorphism through frequency-dependent predation. Evol. Ecol. 19:303-20

Reid DG. 1987. Natural selection for apostasy and crypsis acting on the shell colour polymorphism of a mangrove snail, Littoraria filosa (Sowerby) (Gastropoda: Littorinidae). Biol. J. Linn. Soc. 30:I-24

Reid PJ, Shettleworth SJ. 1992. Detection of cryptic prey: search image or search rate? J. Exp. Psychol.Anim. B 18:273-86

Reillo PR, Wise DH. 1988. An experimental evaluation of selection on color morphs of the polymorphic spider Enoplognatha ovata (Araneae:Theridiidae). Evolution 42: I $172-89$

Robinson MH. 1969. Defenses against visually hunting predators. Evol. Biol. 3:225-59 
Robinson MH. 1990. Predator-prey interactions, informational complexity, and the origins of intelligence. In Insect Defenses:Adaptive Mechanisms and Strategies of Prey and Predators, ed. DL Evans, JO Schmidt, Pp. I29-49. Albany, NY: SUNY Press

Rowell CHF. 197I. The variable coloration of the acridoid grasshoppers. Adv. Insect Physiol. 8:145-98

Royama T. 1970. Factors governing the hunting behaviour and selection of food by the great tit (Parus major L.). J.Anim. Ecol. 39:619-68

Sandoval CP. 1994. Differential visual predation on morphs of Timema cristinae (Phasmatodeae:Timemidae) and its consequences for host range. Biol. J. Linn. Soc. 52:34I-56

Sargent TD. 1976. Legion of Night: The Underwing Moths. Amherst, MA: Univ. Mass. Press. 222 Pp.

Sargent TD. 198I. Antipredator adaptations of underwing moths. In Foraging Behavior: Ecological, Ethological and Psychological Approaches, ed. AC Kamil, TD Sargent, Pp. 259-87. New York: Garland STPM

Schweickert R. 1993. Information, time and the structure of mental events: a 25-year review. In Attention and Performance, ed. DE Meyer, S Kornblum, pp. 535-66. Cambridge, MA: MIT Press

Sherratt TN, Harvey IF. 1993. Frequency-dependent food selection by arthropods: a review. Biol.J. Linn. Soc. 48:167-86

Shettleworth SJ, Reid PJ, Plowright CMS. 1993. The psychology of diet selection. In Diet Selection: An Interdisciplinary Approach to Foraging Behaviour, ed. RN Hughes, pp. 56-77. Oxford: Blackwell Sci.

Sinervo B, Calsbeek R. 2006. The developmental, physiological, neural and genetical causes and consequences of frequency-dependent selection in the wild. Annu. Rev. Ecol. Evol. Syst. 37:58I-610

Staddon JER, ed. 1980. Limits to Action: The Allocation of Individual Behavior. New York: Academic. 308 PP.

Staddon JER. 1983. Adaptive Behaviour and Learning. London: Cambridge Univ. Press. 555 Pp.

Stephens DW, Krebs JR. 1986. Foraging Theory. Princeton, NJ: Princeton Univ. Press. 247 Pp.

Tinbergen L. 1960. The natural control of insects in pine woods I. Factors influencing the intensity of predation by songbirds. Arch. Néerl. Zool. 13:265-343

Tucker GM. 199I.Apostatic selection by song thrushes (Turdus philomelos) feeding on the snail Cepaea hortensis. Biol.J. Linn. Soc. 43:I49-56

Vane-Wright RI. 1980. On the definition of mimicry. Biol. J. Linn. Soc. 13:1-6

von Uexküll J. 1934. Streifzüge durch die Umwelten von Tieren und Menschen. Berlin: Springer. I0I pp.

Wente WH, Phillips JB. 2003. Fixed green and brown color morphs and a novel colorchanging morph of the Pacific tree frog Hyla regilla. Am. Nat. 162:462-73

Whiteley DAA, Owen DF, Smith DAS. 1997. Massive polymorphism and natural selection in Donacilla cornea (Poli, I79I) (Bivalvia: Mesodesmatidae). Biol. J. Linn. Soc. 62:475-94 
Willis AJ, McEwan JWT, Greenwood JJD, Elton RA. 1980. Food selection by chicks: effects of colour, density, and frequency of food types. Anim. Behav. 28:874-79

Wolfe JM. 1994.Visual search in continuous, naturalistic stimuli. Vis. Res. 34:I I87-95

Wolfe JM, Horowitz TS, Kenner NM. 2005. Rare items often missed in visual searches. Nature 435:439-40

Wolfe JM, Horowitz TS, Van Wert MJ, Kenner NM, Place SS, Kibbi N. 2007. Low target prevalence is a stubborn source of errors in visual search tasks. J. Exp. Psychol. Gen. 136: In press

Wolfe JM, Oliva A, Horowitz TS, Butcher SJ, Bompas A. 2002. Segmentation of objects from backgrounds in visual search tasks. Vis. Res. 42:2985-3004

Zentall TR. 2005. Selective and divided attention in animals. Behav. Processes 69:1-15 